\title{
PERSUASÃO ANTES QUE CONVENCIMENTO: APONTAMENTOS SOBRE WITTGENSTEIN E A PSICANÁLISE
}

\author{
João José Rodrigues Lima de ALMEIDA ${ }^{1}$
}

- RESUMO: As relações que Wittgenstein mantém com o pensamento de Freud, como atestaram vários estudiosos, são marcadamente ambíguas: existe, por um lado, uma crítica acerba do caráter pseudocientífico com que a psicanálise apresenta supostas "descobertas empíricas", e do fascínio exercido por este modo de proceder; mas há, por outro lado, evidências da sua admiração pelo efeito dissolvente do uso de metáforas e interpretações, chegando mesmo Wittgenstein a incorporar essa estratégia ao seu próprio método de investigação lógica dos conceitos filosóficos. Neste trabalho pretendo retirar de uma reflexão acerca do método incorporado às Investigações Filosóficas, comparável em muitos aspectos à clínica de uma psicanálise lingüística dessubstancializada, alguns pontos positivos que se poderiam acrescentar à crítica da concepção de linguagem de Lacan.

- PALAVRAS-CHAVE: Wittgenstein; terapia conceitual; teoria da linguagem; psicanálise; Lacan.

1.

No primeiro trimestre de 1938, Wittgenstein anotou uma observação em inglês no seu caderno (MS-158, p.34r): "Eu não estou the ensinando nada; eu estou tentando persuadi-lo a fazer algo. O que nós fazemos é muito mais parecido à Psicanálise do que você poderia dar-se conta" (in: Wittgenstein,

1 João José Rodrigues Lima de Almeida é Doutor em Filosofia pela Universidade de Campinas-Unicamp e Professor Substituto do Departamento de Antropologia, Política e Filosofia da Universidade Estadual Paulista-Unesp, campus de Araraquara. Artigo recebido em set/07 e aprovado em dez/07. 
2000. O sublinhado é do original). A reflexão prossegue até circunscrever a idéia de que o método filosófico escolhido é o de atuar sobre a vontade, não sobre o intelecto.

\subsection{1.}

Esta atitude filosófica, que passa a caracterizar o pensamento de Wittgenstein logo depois do seu retorno a Cambridge - "O filósofo aspira a encontrar a palavra liberadora, isto é, a palavra que finalmente nos permita pegar o intangível que até então tem pesado sobre a nossa consciência" (TS 213, s. 409, in: Wittgenstein, 1993b, p.164) -, refina-se através da investigação dos conceitos matemáticos, lingüísticos e psicológicos, e chega à sua culminância no apuro do texto da primeira parte das Investigações Filosóficas (Wittgenstein, 2004). Uma orientação que se prolonga até as derradeiras anotações, quando o nosso filósofo ainda reflete sobre o valor da persuasão diante dos argumentos:

Quando dois princípios que se encontram não podem se reconciliar, então um qualifica o outro como tolo e herege.

Eu disse que "combateria" o outro, - mas eu não poderia fornecer-lhe razões? Claro; mas até onde elas chegariam? No fim das razões está a persuasão. (Pense no que ocorre quando os missionários convertem os nativos.) (Wittgenstein, 1969b, §§ 611-612)

\subsection{2.}

A atuação terapêutica consiste em correlacionar certos entraves, certas sombras metafísicas, certas imagens que se depositam na nossa linguagem comum, a uma übersichtliche Darstellung, uma "apresentação panorâmica" daquilo que fazemos quando usamos a linguagem. Essa correlação se efetiva através de analogias ou encadeamentos possíveis na gramática do paciente com o propósito de conseguir uma conversão que lhe faça enxergar diferente as mesmas coisas e o libere de problemas filosóficos.

Uma das principais fontes da nossa falta de compreensão é que não temos uma visão panorâmica do uso das nossas palavras - falta à nossa gramática uma visão panorâmica. Uma apresentação panorâmica facilita a compreensão, que consiste precisamente em "ver as conexões". Daí a importância de se achar e de se inventar os encadeamentos. (Wittgenstein, 2004, § 122)

\subsubsection{1.}

Se digo que esta mesa diante de nós não é sólida, porque a madeira da qual é composta consiste de elétrons tão rarefeitos que quase podemos 
chamar o espaço que ocupam de vazio, temos aí um mau uso da palavra "solidez" (cf. Wittgenstein, 1969a, p.45-6). O efeito bizarro aparece porque uma imagem científica, proveniente do conceito de "elétron", misturou-se à gramática do conceito de "solidez". É sobre a imagem que nos aprisiona que serão estendidas as comparações, as analogias e os encadeamentos terapêuticos.

\section{1}

Pode parecer estranha essa aproximação da atitude filosófica das investigações wittgensteinianas à estratégia da psicanálise, já que, afinal, é sabido que nosso autor ficou extremamente furioso somente com a sugestão, publicada num artigo de divulgação da filosofia britânica contemporânea em 1946, de que "na sua concepção, a filosofia era uma forma de psicanálise" (Malcolm, 1977, p.56). Malcolm ouviu pelo menos duas vezes Wittgenstein atacar explicitamente esse tipo de aproximação, dizendo que ela se baseava numa confusão. A sua forma de filosofia e a psicanálise eram, a seu ver, "técnicas diferentes" (idem, p.57).

\section{2.}

No entanto, para jogar mais lenha no fogo das aparências de ambigüidade tão característica do método wittgensteiniano, Bouwsma relata que quando nosso autor submeteu uma monografia a uma comissão de Cambridge para a sua efetivação como professor, 72 das 140 páginas do texto, mais da metade, estavam devotadas à idéia de que a filosofia era semelhante à psicanálise. Um mês depois, ainda, Keynes o encontrou e disse que estava muito impressionado pela idéia que "filosofia é psicanálise. E que seja." (Bouwsma, 1986, p.36).

\section{3.}

Justamente por isso afigura-se como bastante adequada a reflexão de McGuinness (1998, p.27-8) a respeito de uma citação das Vermischte Bemerkungen (1998, p.42) em que Wittgenstein declara que a real originalidade da psicanálise vem de Breuer, não de Freud. Wittgenstein, na verdade, estava se comparando preocupadamente a Freud. Ele achava que o seu tipo de originalidade era mais fecundante que genuína: o seu pensamento consistia em reproduzir o pensamento dos outros de uma forma mais aprimorada, e, por isso, ele era, assim como Freud, comparável a um solo mais fértil, 
no qual uma semente poderia produzir com mais proficiência. Mas Breuer, não, ele era o germe real da psicanálise.

\subsubsection{1.}

McGuinness interpreta que Breuer chamava a atenção de Wittgenstein porque soube renunciar à consecução de idéias meramente hipotéticas para dentro do terreno, duvidoso nesse caso, das descobertas científicas reais. Junto com outra citação das Vermischte Bemerkungen -

Deixar-se psicanalisar é, de certo modo, semelhante a comer da árvore do conhecimento. O conhecimento recebido nos coloca (novos) problemas éticos; mas em nada colabora para a sua solução. (idem, p.40)

- pode-se inferir que, para Wittgenstein, os perigos implicados por essa nova arte, que conquista adeptos pela força das suas metáforas e por resolver enigmas insondáveis como se estivesse processando incógnitas de uma equação, são, de fato, muito maiores do que os seus ganhos:

Freud prestou um mau serviço com as suas pseudoexplicações fantásticas (precisamente porque elas são engenhosas [geistreich]). (Agora qualquer asno pode com a sua ajuda [dessas imagens] "explicar" os sintomas.) (ib., p.62-3)

\section{4 .}

É nesse espírito que também Bouveresse (1991, p.13-53) coloca um enfático ponto de interrogação quando usa a expressão "discípulo" ou "seguidor" de Freud, recolhida das conversas de Wittgenstein com Rhees (Wittgenstein, 1966, p.41). Wittgenstein era um discípulo duvidoso de Freud, ou, pelo menos, bastante atípico. Assinala Rhees (id., ib.) que Wittgenstein admirava Freud pelas observações e sugestões dos seus textos; por ter algo a dizer mesmo quando parecia estar completamente equivocado. Nosso autor dizia que para aprender-se algo de Freud, a pessoa deveria ser crítica; mas a psicanálise geralmente tratava de anular essa qualidade.

\section{5.}

$\mathrm{E}$, de fato, na lista dos autores que influenciaram decisivamente o seu pensamento não figura o nome de Freud (cf. Wittgenstein, 1998, p.16). Apenas, como o reprodutivo Freud, Wittgenstein acrescenta: "O que eu invento são novas comparações." (id., ib.) 
Mas não quero reduzir-me às semelhanças, diferenças e conflitos de Wittgenstein com Freud. Depois dos textos de Cioffi (1998), McGuinness (1998), Bouveresse (1991), e, sobretudo, Baker (1997), apenas para mencionar os quatro mais conhecidos e brilhantes, e depois que a crítica já está razoavelmente assentada, parece-me sensato seguir a própria sugestão de Wittgenstein e partir para "aprender algo de Freud" (cf. Wittgenstein, 1966, p.41).

\section{1.}

Com a expressão "aprender algo de Freud" quero indicar uma interpretação um pouco mais ousada do que ater-se somente a refletir sobre o que possivelmente nosso autor teria assimilado da mitologia psicanalítica para conformar o seu método e as suas intervenções terapêuticas nos conceitos matemáticos, psicológicos e lingüísticos tradicionais. Ao tentar esse salto em altura, bastante mais arriscado ao malogro, espero tecer algumas especulações sobre esse método de investigação lógica do pensamento, tal como aparece no texto publicado das Investigações Filosóficas. Esse texto é o resultado de mais de dezesseis anos de obsessivas revisões, que finalmente transformaram um livro pretendido num álbum consignado (cf. Pichler, 2004). O que quero sugerir é que, aparentemente, a autoterapia conceitual coincide fortemente - e avant-la-lettre - com a clínica de uma psicanálise lingüística como a de Lacan, por exemplo.

\subsection{1.}

Uma "clínica de uma psicanálise lingüística" significa aqui a parte prática da proposta psicanalítica, sem a parte sobressalente da teoria. Pois, como ressalta Bouveresse (1991, p.52-3), de nada serve tentar resolver as concessões de Freud ao materialismo vulgar, ao biologismo e à energética, substituindo-as pela primazia do significante sobre o significado. Wittgenstein conservou-se durante toda a vida interessado nas formas da linguagem, mas, obviamente, depois do seu retorno a Cambridge em 1929, as concebeu de modo plural, não mais de uma maneira sublimada (cf. Wittgenstein, 2004, §§ 89, 94).

\subsubsection{1.}

Por firmar-me apenas no que o Wittgenstein tardio passou a compreender como "lógica", ou como "forma", é que respondo de maneira distinta à 
pergunta de Bouveresse acerca de qual dos dois - Lacan ou Wittgenstein manteve-se mais próximo do espírito da obra de Freud (1991, p.53). Bouveresse pensa que o filósofo austríaco poderia ser chamado de um anti-Lacan avant la lettre; neste artigo defendo que essa crítica cabe geralmente à lingüística estrutural e à topologia, mas não à sua clínica eminentemente antipsicológica e à parte teórica que lhe corresponde.

\subsubsection{2.}

De uma clínica psicanalítica destituída da parte dogmática deve sobrar apenas o fundamento necessário para efetuar as regras do jogo.

\section{3.}

Um salto em altura consiste em abandonar o solo do texto e alçar a patamares distintos, mas sem perder o apoio. Louis Sass (2001), a meu entender, perdeu o apoio. Dado o fato de que os comentários de Wittgenstein a Freud são esparsos e assistemáticos, esse autor pretendeu especular como seria um "estilo wittgensteiniano de psicanálise" (p.255) recorrendo às reflexões de Waismann sobre "vontade e motivo". O efeito, como não poderia deixar de ser, foi uma crítica à psicologia pragmático-causalista de Davidson, Rorty e Marcia Cavell que recaiu na fenomenologia (cf. idem, p.275).

\section{1.}

Sass interpreta que no ensaio inacabado dos anos 40, "Vontade e Motivo", Waismann (2000) não se restringiu, como Wittgenstein, apenas à análise conceitual, ou das formas lingüísticas, ou gramaticais dos conceitos psicológicos, mas combinou a gramática com uma "abordagem mais empírica, fenomenológica, que aspira a elucidar os próprios fenômenos psicológicos" (Sass, 2001, p.275). É de se discordar que um autor que indica claramente que "o conceito de motivo não tem existência real, mas também não é irreal" (cf. Waismann, op. cit., p.295), que afirma que "para descrever o psíquico há necessidade de uma linguagem que seja também instável..." (id., ib., o itálico é do original), que variou os exemplos nos quais a palavra "motivo" parece bem aplicada, e nos quais ela parece ser apenas "mitologia" (ib., p.284), esteja fazendo realmente fenomenologia, hermenêutica ou análise empírica.

\subsection{1.}

Em todo caso, deve-se frisar que a confusão de Sass parece estar contida na imagem de que a investigação wittgensteiniana dos conceitos psi- 
cológicos, não sendo psicológica, possa, por isso, ser interpretada como "abstrata". Dizer que "só no fluxo da vida as palavras têm o seu significado" (Wittgenstein, 1990, § 913; cf. tb. 1981, § 173; MS 169, p.47v, in: 2000; e Malcolm, 1977, p.93) significa afirmar que os jogos de linguagem, as regras gramaticais, dissolvem-se nas multifacetadas formas de vida e são delas, na verdade, inseparáveis. O espírito prático das investigações lógico-filosóficas de Wittgenstein permanece mesmo quando, por exemplo, examinamos a "autonomia da gramática" ou o seu aspecto "transcendental" (cf. Moreno, 2005, p.78-84): nada que é necessário torna-se, só por isso, universal e fixo. Isto posto, podemos descrever sem receio de um desvio para o estratosféri$\mathrm{Co}$, mas também sem o desvanecimento no empírico, a experiência organizada em conceito, isto é, as variadas formas de apresentação da linguagem no tempo e no espaço, porque a sua concretude previne contra o risco eventual de apontar "quimeras" (Wittgenstein, 2004, § 108).

\section{2.}

O que realmente interessa, à diferença de Bouveresse, é dizer que o espírito da obra de Freud coincide na clínica lacaniana e no método wittgensteiniano: são ambas vertentes pragmáticas que lidam com formas lingüísticas constituídas a priori e cujo único objetivo não é a proposição de novas teorias às quais o paciente deve aderir, o convencimento, mas a sua cura.

\subsection{1.}

Assim, as dispersas reflexões de Wittgenstein sobre Freud e a psicanálise, não servem para tirar conclusões sobre a psicanálise. Mas serviriam para curar a doença filosófica da psicanálise e revelar as suas falsas necessidades inconscientes:

É uma atividade primordial da filosofia alertar contra falsas comparações. Alertar contra falsas metáforas que nossos modos de expressão - sem que delas sejamos totalmente conscientes - tomam por fundamentos.

Creio que o nosso método se assemelha aqui com o da psicanálise, que quer tornar consciente o inconsciente e, assim, neutralizá-lo, e creio que essa semelhança não é puramente superficial. (MS 109, p.174; in: Wittgenstein, 2000)

\subsection{2.}

A clínica de Lacan, do mesmo modo, atua para dissolver o sofrimento psíquico: ela nada mais faz senão levar bastante a sério uma gramática, ou 
seja, a regra fundamental da psicanálise dissolvida no tempo: "A transferência é uma relação essencialmente ligada ao tempo e ao seu manejo" (1966a, p.844). Lacan dessubstancializa o inconsciente freudiano na temporalidade mediante uma determinada forma de ação: só a posição estratégica do analista diante da fala do paciente é capaz de imprimir uma direção de cura.

\section{3.}

Se temporalizássemos também os conceitos lingüísticos e a topologia de todas as fases da teoria de Lacan, encontraríamos na clínica psicanalítica a forma da linguagem no fluxo da vida, isto é, inseparáveis do setting analítico, impossibilitando tanto as abstrações teóricas quanto as lingüísticas em função da cura do paciente. Desse modo, poderíamos trazer de volta as palavras da metafísica para o seu uso cotidiano (cf. Wittgenstein, 2004, § 116).

\subsection{1.}

Temos em Wittgenstein uma filosofia da psicanálise como terapia da psicanálise: "O filósofo cuida de um problema como uma doença" (idem, § 255).

4.

Tomemos, por exemplo, as concepções estruturais de masculinidade e feminilidade propostas por Lacan em 1973 (1975, p.99-113). Logo no começo da sessão referida deste seminário, Lacan enfatiza que esses conceitos significam "posições de saber", isto é, lugares que se ocupam na fala, compreendida como um vínculo social de um certo tipo. Isto é, a masculinidade e a feminilidade representam, como auto-identificações possíveis, alguém que tem uma resposta simbólica (ou imaginária), uma "certeza", digamos, certeza esta que se apóia não em si mesma mas em "outro", da mesma maneira como ele já havia ensinado a respeito da doutrina dos "quatro discursos" em outra ocasião (cf. Lacan, 1991).

\section{1.}

Suas concepções de masculinidade e de feminilidade, ou, mais textualmente, de "homem" e de "mulher", são supostamente importantes para serem usadas na clínica como uma versão estruturalista mais sofisticada, 
capaz de abarcar numa só visada os conceitos psicanalíticos centrais de complexo de Édipo, de inconsciente e de sexualidade como recalque, que, se em Freud eram tratados de maneira empírica, aqui passam a ser apenas formas vazias de conteúdo, lembrando muito o conceito de "gênero" da antropologia.

\section{2.}

Como Lacan não trabalha com essas concepções de maneira discursiva, ele trata de instituir formalidades lógicas cuja pretensão é subsumir em poucas "letras" (Lacan sempre joga com as homofonias enganadoras da palavra "lettre", na medida em que para ele este é também um termo sinônimo de "significante"), todo um vasto ensino teórico de psicanálise. Eis, então, as formas lógicas das auto-identificações do "ser falante" como "homem" e como "mulher".

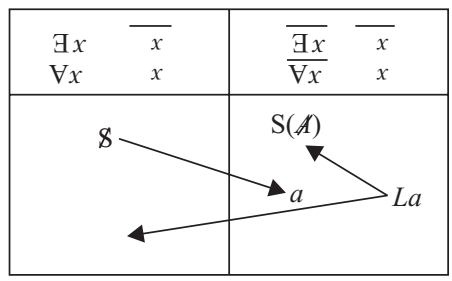

\subsection{1.}

Trata-se de uma tabela complexa, com quatro células repartidas entre duas colunas e duas linhas. Na linha de cima, temos quatro fórmulas quantificacionais, duas à esquerda e duas à direita. Lacan afirma que "Quem quer que seja ser falante, se inscreve de um lado ou de outro" (1975, p.100).

\subsection{2.}

Pois bem, tomemos os seres humanos (os falantes), que "se inscrevem", como diz Lacan, como um todo, como "homem". As fórmulas que se encontram do lado esquerdo da linha de cima, indicam que existe um $x$ para o qual a função $\Phi$, que se aplica universalmente, é negada. Trata-se de um raciocínio hegeliano, para o qual o conceito, tomado como abstração universal, se afirma em contradição com uma particularidade. A particularida- 
de, por sua vez, contradiz o conceito porque, enquanto este se afirma pelas notas comuns a todas as particularidades, aquela reserva idiossincrasias que a afirmam, contraditoriamente, como diferença da identidade. Lacan designa essa velha conhecida máxima da lógica hegeliana com o remoque "o universal se funda pela exceção".

\subsubsection{1.}

Devemos observar que, nessa lógica, a diferenciação não é somente numérica, mas também qualitativa, o que, por outra parte, a diferencia igualmente da lógica clássica formal.

\subsection{3.}

A porta da qualidade abre por isso, para Lacan, a oportunidade de agregar à fórmula o raciocínio, pertencente à tradição da psicanálise, de que se todos somos castrados, isso só ocorre por contradição com o fato de que há pelo menos um ente em particular que não o é. É o que esse autor chama de "função do pai", a qual também sugere a "inexistência", para todos, do "gozo".

\subsubsection{1.}

Não há confusão numa lógica que, de saída, se define extensivamente como compreensão da quantidade e da qualidade.

\subsubsection{2.}

Mas há em Lacan um acréscimo, uma colagem, uma conexão ou uma associação humeana, como se queira, entre um modo de pensar e uma fórmula lógica.

\subsubsection{3.}

Uma frase do tipo - "O corpo humano se acha modelado e dividido pela tripartição dos registros do real, do simbólico e do imaginário" (André, 1987, p.103) - seria tremendamente confusa se fosse compreendida não como metáfora, mas como dado empírico. Essa afirmação não pode ser negada, nem relativizada, sem perda de sentido. Uma metáfora deveria ser 
tratada como tal, sem converter-se em sociologia ou psicologia empírica. (Cf. em Simanke, 2002, uma reflexão sobre o caráter metafórico da teoria lacaniana.)

\section{4.}

Do lado direito da parte de cima da tabela, temos "a inscrição da parte mulher dos seres falantes" (idem, p.101). Essa parte, pelo que se entende, não é uma necessidade, é uma opção. Uma pessoa tem a escolha de se colocar como $\Phi x$ ou de não sê-lo. Se um ser falante se inscreve como "mulher", será "não-todo", como reza a fórmula.

\subsection{1.}

Se temos, então, "o homem" como totalidade fundada pela exceção, ficamos também, por outro lado, com a particularidade "uma mulher", que não pode ser completa.

\subsection{2.}

"Homem" e "mulher" já não são mais, aqui, "sexos", mas "formas de gozo", por assim dizer. Não é simplesmente que o empírico tenha sido recozido pelo transcendental, mas, de modo mais prosaico, que a realidade não é senão "realidade psíquica" ou "fantasia". Em termos lacanianos, a divisão fundamental do sujeito já não mais lhe permite a relação sexual senão pelas alternativas sublimadas do "gozo fálico" (homem) ou do "gozo Outro" (mulher).

\subsection{3.}

A tradição psicanalítica tem o condão - ou a infelicidade - de definir a feminilidade pela masculinidade.

4.5.

Do lado de baixo da tabela encontamos as "identificações sexuais da humanidade" (cf. ib., p.101). À esquerda está o "homem", para o qual encontramos dois símbolos, o $\$$ e o $\Phi$, que para Lacan são significantes. O primeiro é o que ele chama de $S_{1}$, um significante que não pode ter significado, também ele uma exceção que funda a totalidade deslizante da cadeia de significantes, e, portanto, uma espécie de guardião lógico do "fracasso do sentido". O segundo, é o significante fundamental do desejo, o "Falo", que é o seu suporte identificatório. Há uma seta que parte do $\$$ e vai para o outro 
lado unir-se ao símbolo a. Este a é o desejo do "Outro" tomado como objeto, isto é, o desejo do desejo do Outro. Em termos lacanianos, o "objeto causa do desejo". A conjunção dos dois símbolos chama-se "fantasia": é preso a uma fantasia que se "compreende" (em ambos os sentidos) o sujeito, isto é, o sujeito fundamentalmente cindido pela impossibilidade da relação sexual.

\section{6.}

Do outro lado, temos o campo que só se pode identificar pelo seu oposto, ou, em outras palavras, não pode ter auto-identificação significante autônoma. Se "o significante representa o sujeito para outro significante" (1961, sessão de 06/12/1961), nessa posição essa representação é ausente. Com isso, Lacan pretende resguardar em sua teoria uma velha tradição freudiana, que ele valoriza como a pergunta sem resposta da psicanálise was will das Weib? ("o que quer uma mulher?"). Um dos símbolos, $L \not \not$, que aponta para o "Falo" e, ao mesmo tempo, para o símbolo $S(\mathbb{X})$, representa formalmente esta ausência de resposta. Este último é o significante do "Outro" que, por definição, é tanto "barrado", por ser fundante do inconsciente, cuja natureza é a completa opacidade, quanto "vazado", por não conter as respostas que lhe dirigimos. Assim, para o ser falante que se posiciona do lado do "não-todo" não há uma identificação senão à diferença. Portanto, uma identificação, por assim dizer, de fora da linguagem, porque seria o que, na relação sexual, aquilo em relação a que se pode dizer do inconsciente, o radicalmente "Outro" (cf., ib., p.102).

\section{5.}

Se aceitamos que a gramática da psicanálise consiste essencialmente, como diz Lacan, na transferência como uma relação ligada ao tempo e ao seu manejo, de que nos serviriam todas as especulações acima sobre a sexualidade recalcada, o inconsciente e o Édipo? Isto é, em que nos ajudariam construções lingüístico-estruturais que pretendem nos dar, através de fórmulas vazias de conteúdo, condições de atualização da teoria psicanalítica tradicional relativizadas às situações particulares?

\section{1.}

Podemos pensar no seguinte: nossas situações particulares, clínicas, necessitam realmente recorrer a fórmulas que cristalizam em forma pura dimensões teóricas que definem a feminilidade pela masculinidade? 


\section{2.}

Podemos pensar também no seguinte: é necessário tamanho grau de complexidade teórica para lidar empiricamente com uma variedade tão numerosa e, na realidade, inabarcável de situações? Não seria essa questão provavelmente melhor resolvida de maneira aberta, com a carga teórica própria de uma gramática, mínima e aplicável, que sempre define essencialmente e a priori tudo o que usamos em nossa vida prática, o que inclui - inclusive - as formas "mulher" ou "homem" em situações particulares em que haja disso necessidade?

\section{3}

Podemos pensar também no seguinte: preservar o espírito da obra de Freud significa preservar, ainda que de maneira formal, também os anacronismos de Freud?

\section{4 .}

E, por fim, podemos pensar também no seguinte: existem definições lingüísticas puras, como a de "significante", intocáveis, imaculadas, que se possam fixar realmente como fórmulas vazias de conteúdo e que representariam a forma da linguagem por excelência sem a psicologia? De alguma coisa que não reflete a luz do sol, não obedece às leis da gravidade e não altera em absolutamente nada a constituição física do mundo, por que valeria realmente a pena acreditar nela?

\subsection{1.}

Este não é um repúdio positivista à metafísica, é apenas uma observação sobre alguns momentos em que a linguagem parece entrar de férias (cf. Wittgenstein, 2004, § 38).

\section{5.}

O fato é que "masculinidade" e "feminilidade", ou "o homem" e "uma mulher", como quer o texto, não parecem ser conceitos que possam ser lidos através de uma forma lógica atemporal. Esses conceitos têm, sim, uma forma a eles vinculada; eles se encontram, sim, nas atitudes das pessoas com relação a uma expectativa social a ser, ou não, preenchida. Mas essas 
formas são inseparáveis dessas atitudes; portanto, estão dissolvidas nas formas de vida, inseparáveis delas, e não parecem, por isso, capazes de serem escritas em fórmulas lógicas sublimadas, menos ainda na forma de significantes correlacionados ou interligados de maneira inexplicável, assim como não conseguiriam disfarçar uma certa bizarrice se fossem convertidas em leis preditivas ou em ferramentas de interpretação sociológica de fenômenos empíricos.

\subsection{1.}

Se levamos em conta que a descrição deve buscar a desassemelhação (idem, § 130), nossa vontade libera-se da imagem que a prende, e torna-se possível pensar nas gramáticas da feminilidade e da masculinidade como jogos de linguagem diferentes: "A indizível diversidade de todos os jogos de linguagem cotidianos não nos chega a ser consciente, porque as roupas da nossa linguagem igualam tudo" (ib., parte II, p.290). Ou ainda:

"Você pode, na realidade, ter completa segurança sobre o estado da mente de outro, mas é sempre segurança subjetiva, não objetiva" - Essas duas palavras apontam para uma diferença entre jogos de linguagem. (ib., ib., p.291)

6.

Temos nas Investigações Filosóficas o modelo mais acabado de terapia conceitual. Ele poderia depurar também uma psicanálise lingüística.

\section{0 .1 .}

Pensar numa "psicanálise wittgensteiniana" seria um contra-senso. Se a filosofia nada pode fundamentar, se não pode tocar de nenhum modo no uso efetivo da linguagem, e se deixa tudo como está, apenas descreve (cf. ib., § 124), então o resultado de uma terapia conceitual da psicanálise é só a psicanálise sem as suas confusões conceituais.

\section{1.}

Para começar, a despeito do que pode ter aparentado até aqui, Wittgenstein nunca afirmou que há só um método de fazer filosofia: "Não existe um método de filosofia, mas há métodos, como há diferentes terapias." (ib., $\S 133)$. Seria como dizer que só há um método para cozer uma determinada 
iguaria. Isso não é verdade. Seríamos capazes de preparar um bom prato de muitas maneiras diferentes. Isso porque existe um método geral, variado em múltiplas facetas, segundo a imaginação e a criatividade de cada um, para desempenhar bem uma determinada tarefa. O que nos oferece Wittgenstein nas suas investigações filosóficas é um método geral para uma boa terapia conceitual (cf. Hilmy, 1989, p.3-6).

\subsection{1.}

Um bom método geral para a clínica psicanalítica da neurose, como recomenda Lacan, é tornar histérica a fala do paciente: só pela pergunta sobre si mesmo pode o paciente despejar a fala, fim da transferência, ao mesmo tempo colocando o psicanalista ora na posição de saber, ora na posição de objeto de desejo.

\section{2.}

Qual é o método geral do terapeuta do pensamento? Ele faz investigações lógicas: "Já é um progresso o reconhecimento do problema filosófico como algo lógico. Com ele vem a colocação correta e o método." (Wittgenstein, 1990, § 256). Isso quer dizer: ele pesquisa os limites do sentidos das palavras no solo da sua aplicabilidade. Mas, entenda-se: já não se trata mais aqui daquela lógica sublimada, essencialista e atemporal do jovem Wittgenstein, tal como aparece no Tractatus (Wittgenstein, 1993a). Nas Investigações, a lógica desceu do seu patamar excelso e passou a fazer parte das formas de vida, traduzindo-se na metáfora dos "jogos de linguagem" (cf. Wittgenstein, 2004, § 23). Há varios jogos de linguagem, a maioria deles muito diferentes uns dos outros; outros, muito semelhantes entre si, e outros ainda às vezes até sobrepostos - a variedade é infinita. O relato de um sonho, por exemplo, é um jogo de linguagem (idem, parte II, p.244); a descrição do aroma do café (ib., § 610), também o é; a descrição de um sentimento (ib., ib., p.245-6), ou de um "clima" numa situação inusitada (ib., § 609), também o são. Tratam-se sempre de experiências organizadas em conceitos, pelos quais podemos esperar que algo se desenrole, se prolongue e se cumpra de um certo modo. Muitos desses jogos também surgem como uma novidade antes desconhecida, enquanto que outra grande parte deles é esquecida e simplesmente desaparece. Os jogos de linguagem estão vinculados a atividades aprendidas por regras numa cultura, corrigidas por normas de "como fazer", mas essas regras não causam o jogo, são parte dele: seria como dizer que jogamos tênis por causa das regras. Mas o que aprendemos, realmente, é uma forma de apresentação, ou uma proposição 
gramatical, que organiza a experiência de uma determinada maneira, interrelaciona os objetos e autoriza transformações lógicas sobre eles (cf. Wittgenstein, 1969b, §§ 167, 321). Não só aprendemos a calcular de uma determinada maneira, podemos estender o jogo a variações infinitas. Em tudo isso há uma lógica a ser descrita e problematizada, se for o caso: "E à lógica pertence tudo o que um jogo de linguagem descreve" (idem, § 56). A descrição da regra, porém, não é a própria regra, é apenas uma interpretação, um outro jogo. No fim das contas, quando a descrições de razões acabam, não há mais regras, só resta nua a atividade (cf. Wittgenstein, 2004, §§ 211, 217).

\subsection{0.}

O conceito de "jogo de linguagem" não se refere a nenhuma teoria sobre a linguagem, como ela é e o que devemos fazer com ela. Não há nada na realidade que deva corresponder forçosamente a um jogo de linguagem. $\mathrm{O}$ conceito, bastante vago por si só, é necessária e suficientemente preciso para os fins a que se propõe: servir como objeto de comparação terapêutico (idem, §§ 130-131).

\subsection{1.}

Numa atividade que se constitui pela gramática, não sobra a vontade como resto. Se as minhas justificações se esgotam, a pá entorta quando atinge a rocha dura, e então digo "isso é o que faço" (ib. § 217), nota-se que a vontade está na própria forma gramatical: vontade é algo que fazemos. Acrescente-se: vontade não é algo que ocorre, como quer o empirista, nem tampouco um elemento transcendental, já que não posso querer querer (cf. ib., $\S \S 611,613)$. O que fazemos implica, portanto, responsabilidade.

\subsubsection{1.}

As exigências de Wittgenstein são arquitetônicas, referem-se apenas à forma: qualquer explicação, se ocorre, é mero ornamento que nada sustenta (ib., § 217).

\subsubsection{2.}

A terapia gramatical incide sobre a vontade presa a imagens: "Uma imagem nos mantinha aprisionados. E não podíamos sair, pois ela estava na nossa linguagem, e ela parecia repeti-la inexoravelmente para nós" (ib., § 115). 


\subsubsection{3.}

A terapia gramatical trabalha com o material fornecido pelo próprio paciente, já que são as suas formas de apresentação que são estendidas em analogias até o limite do sentido, para que se as contemple de forma panorâmica (ib., § 122).

\subsection{2.}

Na clínica, o psicanalista também observa a forma da fala do paciente, com que regras ele joga o seu jogo, a fim de se posicionar segundo o interesse da direção da cura. Pode-se interpretar a psicanálise como um jogo de poderes clinicamente calculado: o que o paciente faz, deve ser gramaticalmente justificado. Na exposição dessas razões, isto é, sempre o material fornecido pelo paciente e nunca qualquer coisa de fora da sua fala, é que se acha o "objeto causa do desejo" a ser "trabalhado".

\section{3.}

Como é o método geral do terapeuta do pensamento? Ele segue os vestígios dos problemas filosóficos que se instalam em nossas gramáticas, no uso das nossas regras, no ponto em que as palavras se chocam contra o muro da linguagem é já não fazem mais sentido, no que se poderia chamar de "ilusões gramaticais" (ib., §§ 96, 110). O método é o da descrição desses problemas, problemas de natureza filosófica, naturalmente (ib.,§§ 109, 124). Como a filosofia não propõe nada, não decobre nada, nem nada explica, o filósofo descreve uma gramática não para determinar a sua correção, o seu acerto, a sua justeza: não se trata de uma finalidade moral. Em vez disso, o terapeuta do pensamento dirige a nossa atenção para o que não nos parece familiar no que nos é familiar, a fim de dissolver esses problemas e devolver a atividade da maneira como ela se encontra no mundo ordinário (ib., § 129): ele introduz objetos de comparação, como os jogos de linguagem, não para iluminar as similaridades, mas para enxergar as dissimilaridades no aspecto das coisas (ib., § 130).

\subsection{1.}

Por ater-se à forma, a clínica da psicanálise não se importa com o conteúdo da fala, nem com a moralidade do paciente. O pejo moral, ao contrário, denuncia o sintoma a ser trabalhado; e o conteúdo do que se fala, para apresentar o agente que lhe corresponde. A dissolução dos sintomas tam- 
bém se dá pela forma: escansões, pontuações, cortes, ou, nos casos estritamente necessários de intervenção direta, proposição de metáforas.

\section{4.}

Como é feita essa descrição? No texto das Investigações instaura-se um debate entre várias vozes, constituindo-se algo semelhante ao que Siqueira (2004, p.22-9) denomina, segundo a teoria de Bakhtin, um diálogo polifônico (Soulez também escreve sobre o diálogo bakhtiniano e o caráter musical do seu modo de composição filosófica, em 2005, p.313-25; cf. tb. Baker, 2003). Não seria muito preciso, por isso, interpretar os diálogos das Investigações como uma conversa entre Wittgenstein e seu interlocutor, ou entre "Sócrates" e seu "discípulo", ou como a "voz da correção" versus a "voz da tentação" (respectivamente, Glock, 1997, p.222; Bouveresse, 1973, p.21; e, Cavell, 1997, p.42). Tais interpretações induzem a pensar num monologismo, mais próprio do diálogo socrático, que faz o outro falar para submeter a sua voz à verdade do protagonista. Perder-se-ia a visão de uma polifonia ateórica e dissolvente, como aparenta ser o caso. Pois é no meio desses diálogos descontínuos, nos quais, às vezes, a voz de um "eu" se funde com a voz de um próximo, ou com a de um terceiro e a de um quarto, nos quais, também às vezes, as narrativas se misturam e se superpõem, que o texto sugere que podemos estabelecer novos arranjos e conexões para o que nos é de há muito conhecido, para o que sempre esteve diante de nós e não enxergávamos. É ali que surgem analogias, comparações e aforismos que debilitam nosso irrefreável impulso a generalizar, que as discussões vão seguindo um caminho tão inusitado que, se tentamos enquadrá-lo, como quem pretende endireitar os labirintos da linguagem, terminamos invariavelmente em paradoxos, como ocorre em vários trechos das Investigações (cf. Stern, 2005).

\subsection{1.}

Não se pode restringir a clínica psicanalítica apenas a dois personagens: o psicanalista e o seu paciente. O jogo desenrola-se, na verdade, entre quatro figurantes, para dizer o mínimo. Se o psicanalista às vezes ocupa na fala do paciente a posição do "saber", e às vezes a posição de "objeto de desejo", teremos, no mínimo, quatro jogadores na "mesa de pôquer", já que o analista nunca estará onde o paciente supõe. O paciente, tampouco ficará fixado a uma posição: variará conforme a "passagem das cartas". Não é exatamente essa a situação que figura aquele modelo que Lacan chama de "Esquema L"? (cf. 1966b, p.429-30). 


\section{5.}

Qual é o objetivo da terapia conceitual? Se as investigações filosóficas de Wittgenstein não têm um objetivo moral, não se pode dizer que na terapia gramatical não exista um componente ético. Além da gramática implicar a responsabilidade da primeira pessoa, não se dissimula na sua atividade terapêutica um caráter combativo, uma ação de luta ("A filosofia é uma luta contra o feitiço do nosso entendimento pelos meios da nossa linguagem" (Wittgenstein, 2004, § 109)) - ou até de guerra. A luta é contra o dogmatismo, mas a guerra é contra "a obscuridade desse tempo", como sugere o prefácio (cf. idem, p.12). Um tempo dominado pelo cientificismo prevalescente na civilização americana e européia, e que ocupa "o espírito da nossa civilização, cuja expressão é a indústria, a arquitetura e a música do facismo \& do socialismo atuais" (Wittgenstein, 1998, p.8). Por isso, pensa Wittgenstein, embora improvável, não seria impossível que o seu livro lançasse alguma luz sobre um ou outro cérebro (cf. 2004, p.12).

\subsection{1.}

A ética da psicanálise é a ética do desejo (cf. Lacan, 1986). O fim da clínica é a responsabilidade diante do "outro", de quem, afinal, é o desejo. Se só podemos falar do desejo em primeira pessoa, isto imediatamente implica um vínculo social do qual não podemos escapar, como tampouco deixar de nos imiscuir. A ética do desejo significa uma postura proativa diante do legado lingüístico que incessantemente nos apela e problematiza individual e socialmente.

7.

Sobre o que não se pode falar, deve-se calar. (cf. Wittgenstein, 1993a, $\S 7)$.

\section{Agradecimentos}

Agradeço a Arley Moreno, Cristiane Gottschalk, Fernanda Reis, Graziela Laureano, Paulo Oliveira e Rafael Ribeiro, do Grupo de Estudos de Wittgenstein do CLE/UNICAMP, a discussão e a crítica desse texto. 
ALMEIDA, João José Rodrigues Lima de. Persuading rather than convincing: notes on Wittgenstein and psychoanalysis. Trans/Form/Ação, (São Paulo), v.30(2), 2007, p.53-74.

- ABSTRACT: The relations which Wittgenstein entertains with Freud's thinking, as indicated by some scholars, are markedly ambiguous: there is, for the one side, an acerbic criticism about the pseudoscientific character with which psychoanalysis presents its supposed "empirical discoveries", and, consequently, the fascination exherted by this kind of procedure. But there is also, for the other side, evidences of admiration by the dissolving effect the use of interpretations and metaphors in psychoanalysis realizes, encouraging Wittgenstein to even incorporate such strategy to his own method of logical investigation of philosophical concepts. In this article I intend to draw some reflection about the method incorporated to the Philosophical Investigations, in several aspects really similar to a clinic of a desubstantialized linguistic psychoanalysis, in order to add some positive points to the criticism usually made to the Lacanian conception of language.

- KEYWORDS: Wittgenstein; conceptual therapy; theory of language; psychoanalysis; Lacan.

\section{Referências bibliográficas}

ANDRÉ, Serge. O Que Quer uma Mulher? Tradução de Dulce Duque Estrada. Rio de Janeiro: Jorge Zahar, 1987.

BAKER, Gordon. "Notre" Méthode de Pensée sur la "Pensée". SOULEZ, Antonia. Dictées de Wittgenstein à Friedrich Waismann et pour Moritz Schlick, v. 2. Études Critiques. Paris: Presses Universitaires de France, 1997, p.283-319.

(ed.). The Voices of Wittgenstein: The Vienna Circle. London: Routledge, 2003.

BOUVERESSE, Jacques. La Rime et la Raison - Science, Étique et Esthétique. Paris: Editions du Minuit, 1973.

Philosophie, Mythologie et Pseudo-Science. Wittgenstein Lecteur de Freud. Paris: L'Eclat, 1991.

BOUWSMA, Oets K. Wittgenstein Conversations, 1949-1951. Indianapolis: Hackett Publishing Company, 1986.

CAVELL, Stanley. Esta América Nova Ainda Inabordável. São Paulo: Editora 34, 1997.

CIOFFI, Frank. Wittgenstein on Freud and Frazer. Cambridge: Cambridge University Press, 1998.

GLOCK, Hans-Johann. Dicionário Wittgenstein. Tradução de Helena Martins. Rio de Janeiro: Zahar, 1997. 
HILMY, S. Stephen. The Later Wittgenstein. The Emergence of a New Philosophical Method. Oxford: Basil Blackwell, 1989.

LACAN, Jacques. Le Séminaire, Livre IX. L'Identification. Texto inédito fotocopiado, 1961.

Position de L'Inconscient. Écrits. Paris: Seuil, 1966a, p.829-50.

La Chose Freudienne ou Sens du Retour à Freud en Psychanalyse. Écrits.

Paris: Seuil, 1966b, p.401-36.

Le Séminaire, Livre XX: Encore. Paris: Seuil, 1975.

. Le Séminaire, Livre VII: L'Ethique de la Psychanalyse. Paris: Seuil, 1986.

. Le Séminaire, Livre XVII: L’Envers de la Psychanalyse. Paris: Seuil, 1991.

MALCOLM, Norman. Ludwig Wittgenstein, A Memoir. London: Oxford University Press, 1977.

McGUINNESS, Brian. Freud and Wittgenstein. Wittgenstein and His Times. London: Thoemmes Press, 1998 [ed. original, 1982], p.27-43.

MONK, Ray. Ludwig Wittgenstein: The Duty of Genius. New York: Penguin Books, 1991.

MORENO, Arley R.. Introdução a uma Pragmática Filosófica: de uma Concepção de Filosofia como Atividade Terapêutica a uma Filosofia da Linguagem. Campinas: Editora da Unicamp, 2005.

PERELMAN, Chaim \& OLBRECHTS-TYTECA, L.. Traité de L'Argumentation. La Nouvelle Rhétorique. Bruxelles: Editions de L'Université de Bruxelles, 4ème éd., 1983.

PICHLER, Alois. Wittgensteins 'Philosophische Untersuchungen': Vom Buch zum Album. Studien zur österreichischen Philosophie, 36. Amsterdan: Rodopi, 2004.

RHEES, Rush (ed.). Recollections of Wittgenstein. Oxford: Oxford University Press, 1984.

SASS, Louis. Wittgenstein, Freud and the Nature of Psychoanalytic Explanation. ALLEN, Richard \& TURVEY, Malcolm (eds.). Wittgenstein, Theory and the Arts. London: Routledge, p.253-95, 2001.

SIQUEIRA, Eduardo G. Por Uma Gramática do Querer em Wittgenstein, 2004. Tese (Doutorado em Filosofia). Instituto de Filosofia e Ciências Humanas, Universidade Estadual de Campinas, Campinas, 2004.

SIMANKE, Richard T. A Letra e o Sentido do 'Retorno a Freud' de Lacan: A Teoria como Metáfora. SAFATLE, V. (org.). Um Limite Tenso: Lacan Entre a Filosofia e a Psicanálise. São Paulo: Editora da Unesp, 2002, p.277-303.

SOULEZ, Antonia. A Case of Early Wittgensteinian Dialogism: Stances on the Impossibility of 'Red and Green and the Same Place'. PICHLER, Alois \& SÄÄTELA, Simo (eds.) Wittgenstein: The Philosopher and His Works. Working Papers from the Wittgenstein Archives at the University of Bergen, n. 17, 2005, p.313-25.

STERN, David. How Many Wittgensteins?. PICHLER, Alois \& SÄÄTELA, Simo (eds.) Wittgenstein: The Philosopher and His Works. Working Papers from the Wittgenstein Archives at the University of Bergen, n. 17, 2005, p.164-88. 
WAISMANN, Friedrich. Volonté et Motif. SCHLICK, Moritz \& WAISMANN, Friedrich. Questions d'Étique \& Volonté et Motif. Textos traduzidos do alemão por Christian Bonnet. Paris: Presses Universitaires de France, 2000.

WITTGENSTEIN, Ludwig. Philosophical Investigations (Philosophische Untersuschungen). Tradução de G. E. M. Anscombe. Oxford: Basil Blackwell, 1958.

Lectures and Conversations on Aesthetics, Psychology \& Religious Belief. Edited by Cyril Barrett. Oxford: Basil Blackwell, 1966.

The Blue and Brown Books: Preliminary Studies for the 'Philosophical Investigations'. Oxford: Basil Blackwell, 1969a.

On Certainty (Über Gewissheit). Tradução de G. E. M. Anscombe. Oxford: Basil Blackwell, 1969b.

Last Writings on the Philosophy of Psychology. Preliminary Studies for Part II of Philosophical Investigations, v. 1. Ed. Por G H. Von Wright \& Heikki Nyman. Oxford: Basil Blackwell, 1990.

Tractatus Logico-Philosophicus (Logisch-Philosophische Abhandlung). Tradução de Luiz Henrique Lopes dos Santos. São Paulo: Edusp, 1993a.

Philosophical Occasions 1912-1951. Edited by James Klagge \& Alfred Nordmann. Indianapolis: Hackett Publising Company, 1993b.

Culture and Value (Vermischte Bemerkungen). Tradução de Peter Winch, texto revisado por Alois Pichler. Oxford: Basil Blackwell, 1998.

Wittgenstein's Nachlass: The Bergen Electronic Edition. Oxford: Oxford University Press, 2000.

Philosophische Untersuchungen. Kritisch-genetische Edition. Herausgegeben von Joachim Schulte in Zusammenarbeit mit Heikki Nyman, Eike von Savigny und George Henrik von Wright. Frankfurt: Suhrkamp Verlag, 2001.

Philosophische Untersuchungen. Auf der Grundlage der Kritisch-genetischen Edition neu herausgegeben von Joachim Schulte. Frankfurt: Suhrkamp Verlag, 2003.

Investigações Filosóficas. Tradução de Marcos G. Montagnoli. Petrópolis: Ed. Vozes, 2004. 